\title{
Sustainable transport: From high carbon to carbon neutral
}

\begin{abstract}
Purpose - This paper seeks to explore the transition and process of migrating from high dependence on internal combustion engine (ICE), to one that is a sustainable carbon neutral fleet.

Design/Methodology/Approach - Comparative studies will be completed for commercial vehicles with combustion engines and carbon-neutral alternative vehicles.

Findings - This paper provides informed decision for people who may wish to consider alternative sustainable carbon neutral propulsion systems.

Practical implications - Historically, modes of transportation rely on the conversion of chemical (stored) energy to motion via the use of internal combustion engine (ICE). However, with more awareness, rise in "Green" consumers, and government policies, businesses are open to exploring sustainability and reducing their carbon footprint contribution to the environment.

This study suggests that there will be some level of trade-off discussions needed to make such decisions based on the different requirements, industries, geographical locations, and the environment in which such businesses operate. Some companies will be able to justify the need to be more carbon neutral, though some may not, or off-set the capital outlay required to transition and remain carbon neutral, without some form of external help.
\end{abstract}

Keywords: sustainable transport, electric vehicles, commercial vehicles, internal combustion engines, battery electric vehicle, decarbonisation

1 Postgraduate, Student - Leeds Beckett University; e-mail: toyin.onaf@gmail.com

DOI: http://dx.doi.org/10.31570/Prosp_2021_1_6 


\section{Introduction}

Sustainable transport can be described as an active consideration of the emission and carbon footprint of your fleet on the environment. There is a future element in the word "sustainable" and this reflects the ability for something to be able or capable over time. This thus implies that sustainable transportation is a long-term strategic planning process that involves decision making and the recognition of its benefits or value in the long term. The transportation industry is a sector of the economy that supports the movement of goods, people, and infrastructure from source to destination via rail, land, or sea. For the purpose of this research, we will limit our discussion to land transport using cars or vans.

The transport industry relies on energy conversion, based on the principle of energy conservation. Based on data available from the Office of National Statistics (2019), road traffic has increased circa 29\% (see Figure 1 - below) in the last 30 years, with petrol volumes about 4\% higher than diesel between 1990-2017 (ONS, 2019). The detailed breakdown of this composition is beyond the scope of this research, but it is worth noting that there are more offerings in the ultra-low emissions space with $0.5 \%$ of all licensed vehicles in the UK in 2018 having been ultra-low emission vehicles.

Figure 1: Road traffic increased by 29\% from 1990 to 2018

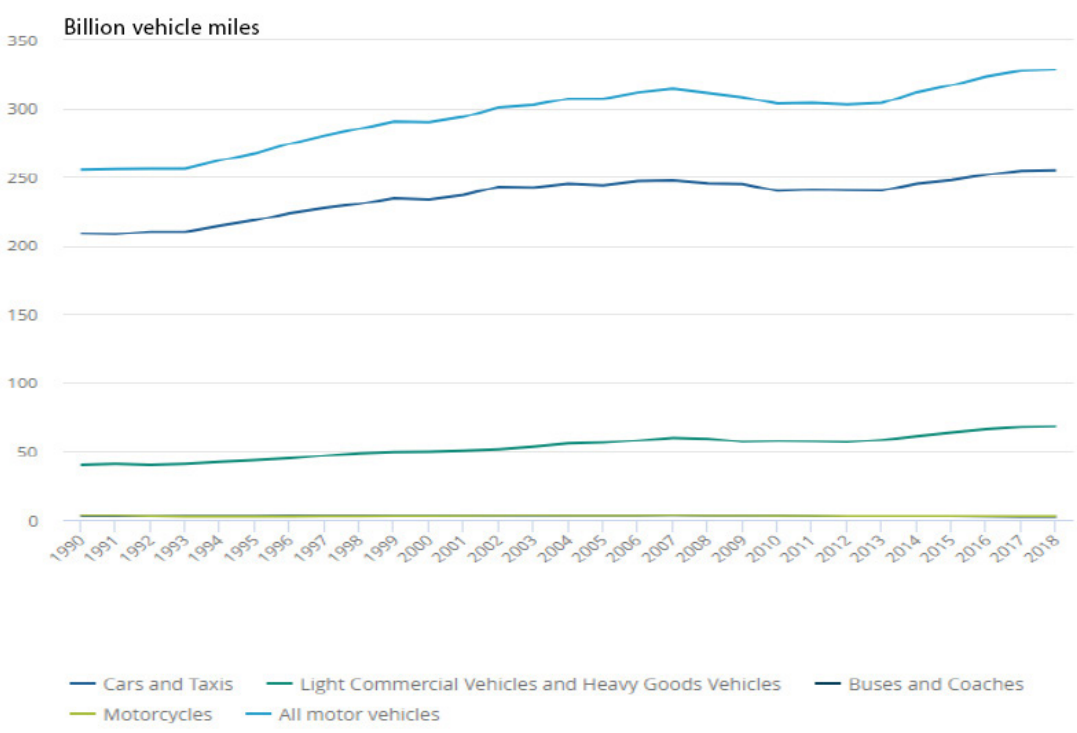


Historically, chemical energy stored in fuel is converted to kinetic energy at the wheels to propel the vehicle. The energy conversion emits greenhouse gases like carbon and nitrogen oxides, that are both harmful to people and the environment. It is these emissions and the implication to the environment that has fuelled a rethink of sustainable alternatives to the current transport systems as we know it.

\section{Literature review}

\section{Sustainable transport}

There are many articles and journals that have defined or described sustainable transport. In this context, the researcher has added the element of value to the definition or description of sustainable transport, to shed more light on this aspect. Sustainable transport is the ability to move living and non-living things from source to destination, through means or methods that are not harmful to the environment. This means of transportation can be for social, commuting, leisure activities, or for the purpose of transporting goods and services. Electric vehicles powered by electrified powertrains, are currently associated with sustainable transport or the term "Green", since they do not directly emit greenhouse gases (GHG). These vehicles are carefully engineered and designed to counteract the internal combustion engine powered vehicles that emit gases at the tailpipe of the vehicle. The concept of Green as an attribute in today's world lends to systems, processes or companies that encourage, promote, or are aligned with the long-term sustainability of the planet. There are different points of view on what constitutes "Green", but many researchers and studies point to the reality that electric vehicles are a growing alternative or substitute to traditional ICE powered vehicle, and in the not-too-distant future, electric vehicles will overtake fossil-fuel powered vehicles and the dominant powertrain of choice in discussions around transportation of passenger and commercial vehicle segments.

For transport companies that use vehicles as a means of delivering value to customers, it is important to consider the impact of the tailpipe emissions of their fleet vehicles to the environment; both from a company point of view, and from the perspective of the customers they serve. In the past, customer preferences did not necessitate companies to consider their environmental impact and sustainability footprint. However, with the focus on climate change, sustainability and the emissions regulations in Europe, more companies are gradually adopting or considering the option of introducing some form of sustainable transport to their services. Whilst going green or using 
sustainable transport is not necessarily an "order winner", recent studies show a gradual appetite for customers aligning with companies that have sustainable or green elements and are active in contributing to the sustainability of the environment.

\section{Types of propulsion systems for commercial vehicles}

For this research, propulsion systems can be classified into:

- Internal combustion engines (ICE): ICE vehicles use a conventional engine to convert the stored energy via the fuel (petrol or diesel), into mechanical actions of the pistons; and finally convert it to kinetic energy at the wheels. The ICE propulsion system has a by-product known as greenhouse gases and these gases, in higher concentration, can be harmful to man and the environment. The European emission standard governs and regulates the emissions of these vehicles for different categories of vehicles. The current standard is Euro 6, and the next emission standard will be known as Euro 7, as Euro 6 is insufficient to reduce the harmful emissions from the vehicles.

- Hybrid vehicles: the hybrid vehicle is one that has 2 or more sources of propulsion; predominantly a mix of ICE and BEV. The ICE option could be a petrol or diesel engine that can be used to complement the battery or charge the battery, subject to the application and its intended use. Fuel cells electric vehicles could also be used instead of the ICE propulsion. The hybrid vehicle has a spectrum of options, from the mild and micro hybrids to the plug-in hybrids and range extenders. Some hybrids are relatively green and help lower the fleet average emissions for automotive manufacturers, to comply with the current EU standards.

- Battery Electric Vehicle (BEV): the electric vehicle is one with electrified powertrain as the primary source of propulsion. Here, energy from the battery is converted to kinetic energy (or moving energy) at the wheels. The EV options include the battery electric and extended range electric options. There are many opinions on the perceived "green status" of this type of propulsion, but the conclusion is that there are less emissions from this propulsion system than the conventional ICE propulsion system, hence the push for some form of electrified powertrain options board. 


\section{Energy sources for propulsion systems}

For this research, energy sources of propulsion systems will be limited to the following:

- Gasoline: this is a derivative of the fractional distillation of crude oil, extracted from the earth's crust. It is relatively volatile input in the combustion process. A key indicator of a gasoline engine is the presence of a spark plug that introduces fire, and hence combustion, in the engine.

- Diesel: this is also a derivate of the distillation process but unlike the gasoline engines, diesel engines use glow plugs to achieve high temperatures required for combustion. They are typically used in larger engines like in ships and heavy-duty vehicles, due to lower flammability and the engines have more fuel economy.

- Battery: batteries are a source of power (hybrid), or the source of power (battery electric vehicles) for battery powered vehicles; sometimes referred to as electrified powertrains. These batteries are installed in vehicles with battery management, cooling, and control systems to support the efficient management of the delivery of power to the vehicles. The batteries are assembled in packs; and the packs arranged in arrays, to provide the required potential energy that is transformed to kinetic energy that propels the vehicle. There are different types, cycles, ratings, and combinations of these batteries, but that is outside the scope of this study.

- Fuel Cells: this system uses reduction-oxidation (Redox) reactions as a means of converting stored chemical energy; mostly hydrogen, to kinetic energy at the wheels. This is less prominent of the energy sources because of the level of current technology in that space, and the economic viability of mass-producing fuel-cell powered vehicles as an alternative to the more established forms of propulsion.

For the purpose of this research, the focus of sustainable transport will be on batterypowered commercial vehicles (CV) or BEV's, as opposed to passenger vehicles (PV's) or heavy goods vehicles (HGV's). BEV's powered vehicles support the initiatives and the desire for countries around the world to reduce vehicle emissions which is a significant contributor to greenhouse gases. It also aligns with the theme of the research which seeks to explore value added by adopting a sustainable carbon-neutral fleet of vehicles. The automobile brand manufacturers that operate in this space include the 
traditional brands like Ford (e-Transit), Nissan (Vivaro-e), and Fiat (e-Ducato), or new startup entries like Canoo, Arrival and Rivian to mention a few. Currently, progress has been made in providing the enabling infrastructure and awareness to support the adoption of BEV's. However, more needs to be done to increase the rate of adoption of these vehicles to support the different carbon neutral initiatives around the world.

\section{Infrastructure, charging options and cost}

The charging options and cost of charge varies geographically, by battery type, and by manufacturer type. These charging systems are based on the Society of Automotive Engineering (SAE) standard J1772, though Tesla and Chademo use different charging solutions, as seen in Figure 2 (Energy.Gov, Vehicle Charging, 2020).

Figure 2: EV Charging Basics (Chargepoint, n. d.)

\section{EV Charging Basics}

\begin{tabular}{|c|c|c|c|c|c|}
\hline Type & $\begin{array}{l}\text { Miles of Range Per Hour of } \\
\text { Charging (RPH) }\end{array}$ & Time to Fully Charge & When to Use & Connector & \\
\hline $\begin{array}{l}\text { Level 1, Standard Wall } \\
\text { Outlet (AC) }\end{array}$ & $5 \mathrm{RPH}$ & $\begin{array}{l}+16 \text { hours for an } 80 \text {-mile battery } \\
+40 \text { hours for a } 200 \text {-mile } \\
\text { battery }\end{array}$ & $\begin{array}{l}\text { + Get some charge while } \\
\text { you sleep } \\
\text { Note: slower for cars with } \\
\text { large batteries }\end{array}$ & $\begin{array}{l}1 \\
\text { t }\end{array}$ & $\begin{array}{l}\text { Note: you'll need your } \\
\text { own cable to plug in } \\
\text { to the wall for Level } 1\end{array}$ \\
\hline $\begin{array}{l}\text { Level } 2 \text { Charging Station } \\
\text { (AC) }\end{array}$ & $\begin{array}{l}\text { +12 RPH for cars with } 3.7 \mathrm{~kW} \\
\text { on-board charger } \\
+25 \mathrm{RPH} \text { for cars with } 6.6 \\
\text { kW on-board charger }\end{array}$ & $\begin{array}{l}+3.5 \text { hours for an } 80 \text {-mile } \\
\text { battery } \\
+8 \text { hours for a } 200 \text {-mile battery }\end{array}$ & $\begin{array}{l}\text { + At work } \\
+ \text { While you sleep } \\
+ \text { Topping up around town }\end{array}$ & & J1772 connector \\
\hline DC Fast Charging & $\begin{array}{l}100 \mathrm{RPH} \text { or more, depending } \\
\text { on the power level of the } \\
\text { charger } \\
+24 \mathrm{~kW} \text { (up to } 100 \mathrm{RPH} \text { ) } \\
+44 \text { to } 50 \mathrm{~kW} \text { (up to } 200 \\
\text { RPH) }\end{array}$ & $\begin{array}{l}\text { Depends on the power level of } \\
\text { the charger and car model, but } \\
\text { could be } 80 \% \text { charged within } 30 \\
\text { minutes }\end{array}$ & $\begin{array}{l}+ \text { Short stops } \\
+ \text { Express Corridor locations }\end{array}$ & $\underset{\substack{\text { SAE Combo } \\
\text { (CCS) }}}{\stackrel{\circ}{\circ}}$ & CHAdeMO \\
\hline
\end{tabular}

Connectors

All EVs except Tesla use the same $\mathrm{J}_{1772^{\mathrm{m}}}$ connector for Level 2 charging. Tesla makes adapters that allow their vehicles to charge using $\mathrm{J} 1772$ or CHAdeMO connectors.

Not all EVs come with DC fast charging as a standard feature. It's often available as an upgrade package.

When choosing a DC fast charging station, check the connector to make sure it fits your car's charging port. There are three different DC fast charging connector standards in are three different DC fast charging connect

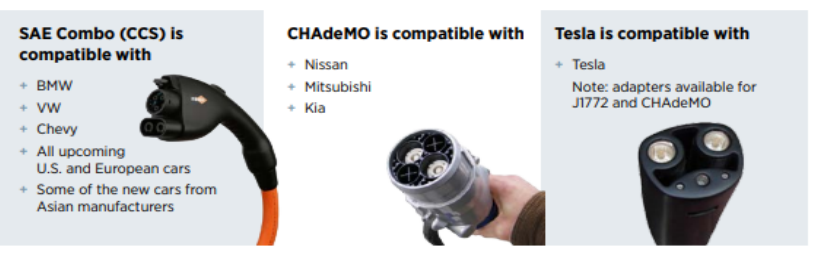

There is a range of charging solutions with different cost implications and mitigating factors that may increase the cost of charging and the health of the battery overtime. However, studies have shown that from a total cost of ownership (TCO) model, EV solutions can be as economically viable as ICE vehicles (Wu-Inderbitzin- Bening,2015). Studies also show that fleet vehicles with high vehicle utilisation could switch to electric vehicles as an economic and strategic alternative to traditional fleet vehicles (Kumar- 
Chakrabarty 2020). Contributors such as a relatively cheap energy source, government incentives such as grants, and less maintenance due to fewer electromechanical parts, may be possible reasons for this solution (EDF, 2020). For charging infrastructure there are different types of charging systems:

- Level 1 or slow charge: this is typically found in the home and charging is done by plugging the EV to a standard power source and delivers about 5 miles of range per hour (RPH).

- Level 2 or Fast charge: this is typically found in public charging stations and some domestic homes. The range is circa 12 to $25 \mathrm{RPH}$.

- DC fast charge: this is typically used for rapid charge that delivers circa $100 \mathrm{RPH}$. These are mainly installations in charge stations rather than domestic installation.

Though the rate of charge is subject to the EV charging port, time of day, availability (for non-residential charging) and the tariff for different providers, charging options and availability has significantly improved overtime (Chargepoint, n. d.).

\section{Range anxiety for transport companies}

Historically, there is little or no range anxiety for ICE vehicles, as there are well established dealer networks in most parts of the world. However, for EVs, the limited battery range on such vehicles and potentially the driving style creates the anxiety of the inability of a driver to successfully complete a journey without the need to recharge batteries. With limited electric charging outlets, that is a concern.

According to Statista (2020), the number of locations in the UK doubled between March 2018 to Jan 2020; with a 110\% increase from 5,024 to 10,616. In Nov 2020, that number has increased to 12,648 ; with $19.5 \%$ of those locations having the rapid charge option. With the right charge solution, network provider, and at optimal cost; with more availability of charging installations to support the rise in demand for EV applications, range anxiety can be minimised.

\section{Emissions}

Emissions are a keenly debated topic due to the difference of opinions and studies on the calculation of emissions in comparative studies (CarbonBrief, 2020). Some consider the emissions at the tail pipe of the vehicle, while others explore the total lifecycle 
ownership of a typical vehicle, as basis for establishing the benchmark for emissions of a vehicle. In considering the lifecycle, the source and destination of all the parts, mode of transportation and the method of extraction and manufacture of the sub-components should also be considered. However, it can be difficult to accurately measure the emissions derived from indirect energy sources and the supply chain required to manufacture the vehicles.

Figure 3: Disparity in research studies for battery lifecycle emissions (CarbonBrief, 2020)

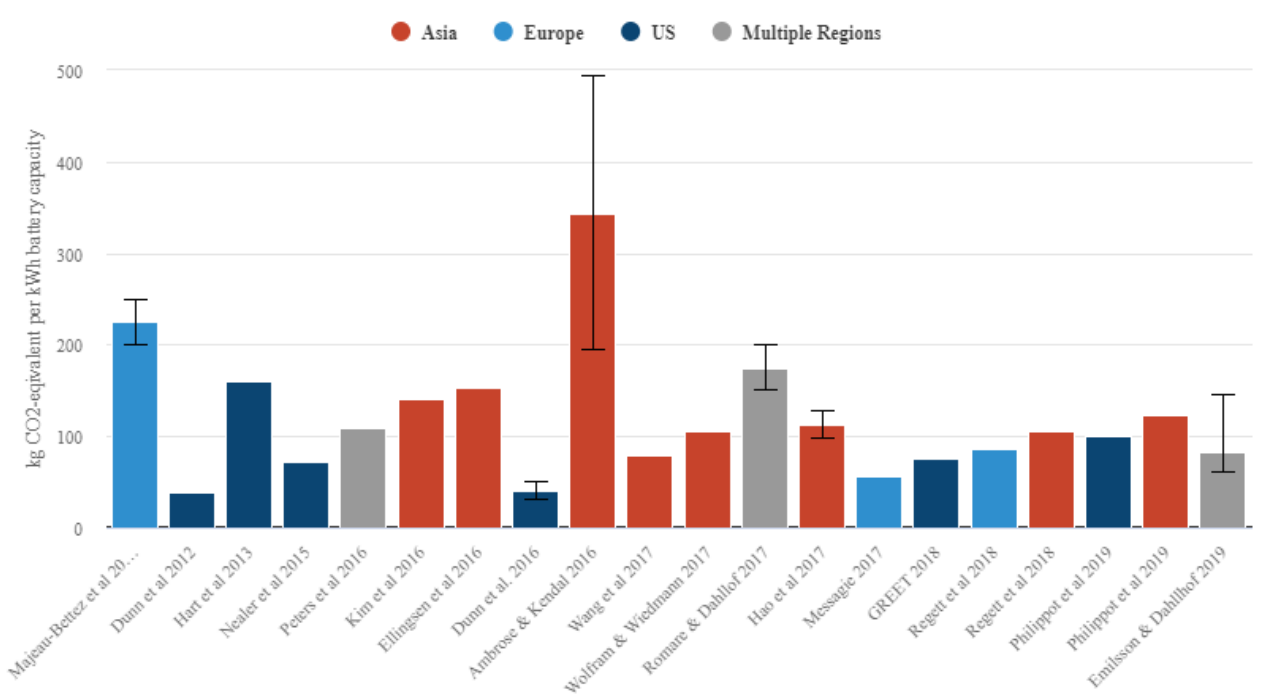

Figure 3 (above) shows the range of differences in studies of battery lifecycle emissions across 17 different studies. Most of these studies indicates a smaller emission lifecycle than the original studies completed, providing further evidence of the notion that electrified powertrain propulsion systems might be the prime direction for auto industry. However, there needs to be greater emphasis on how battery technology is manufactured because of the potentially high energy consumption required to manufacture such batteries. If production is heavily reliant on traditional sources of power generation like coal, the output from the manufacturing process has a direct implication on the lifecycle calculations of emissions, relative to a manufacturing process with renewable or more environmentally friendly energy sources. 


\section{Value of electrified propulsion systems}

There are monetary and desirable elements linked to the word "value", but for this research, the value referred to, is the financial, ethical, and moral value associated with electrified propulsion systems.

- Financial value: this is the monetary value of adopting EV for transport operations. First generation EV's and perhaps the current EV space is perceived to be capital intensive; both to acquire the vehicle(s) and the logistical infrastructure to successfully operate the vehicle(s). This is true for both domestic and commercial applications, and it is one of the biggest barriers in the adoption of EV (McMahon 2019). However, when the lifecycle of the EV is considered, including potential government grants and the customer appeal of being seen as "green", the argument might be more favourable to the consideration of EV.

- Ethical value: this is the value the company places on their responsibility towards their employees, society and the environment. Sometimes these values are a result of the environment or the industry which such companies either operate in or serve. Whilst vehicle manufacturers have direct emissions regulations to adhere to; transport companies, indirectly adhere to these rules by placing orders for compliant vehicles or meeting the restrictions in the environment they operate. An example is the congestion charge imposed on categories of vehicles based on the fuel type and the emissions rating, in some European cities like London and Paris.

- Moral value: this is the value the individual decision makers and employees place on doing the right thing. Decision makers often consider their moral obligation particularly the influence of being "Green" or contributing to the greater good of reduced pollution in major cities. Moral values are good but can be independently insufficient to make a difference to the society. Financial and ethical considerations can sometimes outweigh basic moral principles; especially if the decision making is not unitary. 


\section{Corporate decision making}

According to (Juneja n. d.), decision making is a continuous and dynamic activity that transcends an organisation and is critical to the longevity of the organisation. It is reliant on the ability of the decision makers to holistically understand the parameters for the decision to be made, and select the best possible option, in the interest of the company. Typically, these decisions are made following conversations, discussions and perhaps trade-offs of potential alternative causes of action. In the transport sector, those decisions could include:

- Sourcing of the vehicles.

- Type and brand of vehicle.

- Total cost of ownership of the vehicle - including disposal.

- Value and disposal of current fleet.

- Government policy or regulations that could change operations metrics i. e., introducing the ultra-Low emission zone (ULEZ) in big cities like London.

- Hidden costs when purchasing new vehicles.

- Hidden costs or depreciation of existing vehicles to be disposed or discarded.

- New business won, as a result of decisions made i. e., new business as a result of going electric.

- Cost of after sales and service of the vehicles.

These are critical business decisions for many companies and failure to select the cost-effective solutions could be the difference between profitability and bankruptcy. Sometimes, these decisions are symptomatic of its financial implication to the business, though as previously mentioned, moral and ethical values can also impact the outcome of trade-off studies to determine the best outcome. These decisions may be time-bound or constrained to certain factors and could require further deep-dive or sensitivity analysis, to arrive at the correct conclusion.

Emissions, costs, and sustainability are 3 key metrics or attributes that can support evidence-based decision-making with multi-attribute utilities (MAU's) (JansenCoolen-Goetgeluk 2011). Whilst an in-depth review is beyond the scope of this research, it is worth highlighting the role of robust evidence-based trade-off discussions and their value in helping to arrive at the correct decision. Quantitative data gathered to support the business case, can be expensive and time consuming but cannot be overemphasised; in helping to arrive and make good decisions. 


\section{Adoption of EV in Transport}

Figure 4: Technology adoption (HelloIota, n. d.)

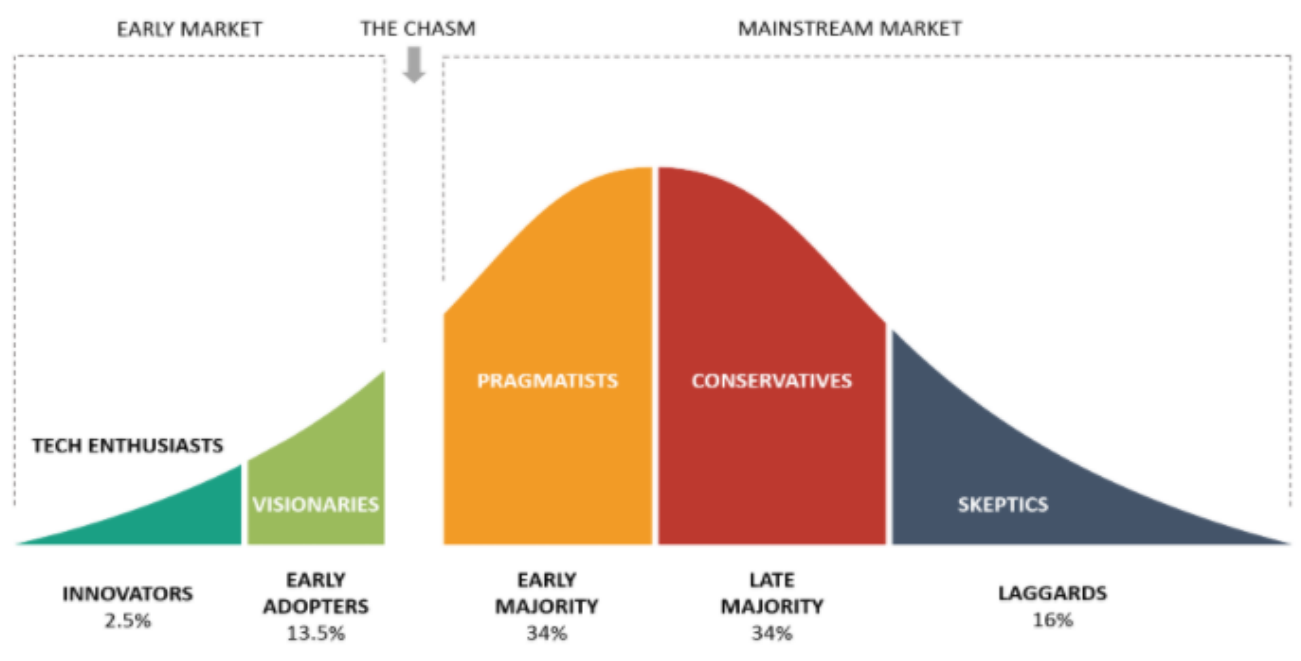

Figure 4 (above), shows the famous technology adoption curve (Hellolota, n. d.). This curve depicts the typical adoption curve for new technology. In the electric vehicle world, companies like Tesla, can be classified as innovators, because they set out specifically to target the relatively new electric vehicle market, without compromise on speed, agility, and handling characteristics of the conventional vehicle (Tesla, 2020). Other vehicle brands in this category include Rivian, Canoo, Workhorse, BrightDrop EV600 and Arrival, who play in the commercial vehicle arena. On the other hand, many traditional automobile manufacturers will fall into the $68 \%$ majority bracket, as they have had to compete in this arena, even though some of them currently have fossil-fuel powered alternatives that are in competition for a market share with the innovators. Ford, Renault, and Nissan are traditional brands who are also playing in the EV arena.

With favourable government policies and incentives, short term or long term, additional charging infrastructure, and a downward trend in the initial capital required to purchase EV alternatives, the transport industry will gradually transition to a high EV mix as opposed to the current high ICE and Hybrid Mix (Mallette-Khanna-Santha 2018). 
Adoption of EV in the transport is driven by some of the following factors:

- Government incentives or grants which can be up to $£ 3,500$ for cars, $£ 8,000$ for vans and $£ 7,500$ for taxis; subject to mileage emission restrictions (Gordon 2019). Some of these incentives are subject to review and may be discontinued or time bound.

- Gradual decline in upfront cost: Initially the cost of EV's were prohibitive but with investment in technologies, more players operating in the field, advancement in science and engineering, information sharing and collaboration across the OEM's, the cost projection is trending downwards. Whilst it is not as cheap as ICE alternatives, there is a growing acceptance by innovators and early adopters of EV who are willing to invest in alternative propulsion systems.

- Investment in infrastructure: With more investment in the charging infrastructure, a bigger range to curb range anxiety and an improvement in the charging experience perceived by customers in charging stations, there is scope for more companies to get involved in the value chain process of the EV experience. This can only be good news to potential adopters, who may be hesitant to forego the luxury of the status quo; i. e., ICE propulsion systems.

- Local \& regional regulations: The more government policy favours tighter emissions requirements and the higher the penalties for breaching such are, the easier it is for individuals and companies to be receptive to the idea of EV's.

- Strategic decision making: Many major cities in Europe and on the continent have city wide emissions targets and plans to further restrict the use of ICE vehicles at certain times of the day. Knowing this, many transport-enabled businesses looking to expand into such markets must consider EV's as an alternative means of transportation. In London, there is the normal congestion charge but there is scope to expand the ultra-low emission zones (ULEZ) beyond the current boundaries. Any transport related business seeking to expand into London will have to contend with these charges, in addition to any other business decisions that need to be made. If there is a similar EV alternative that can serve the needs of the company, it should trigger a trade-off discussion between investing in ICE vehicles plus congestion charges or exploring a competitive and comparative EV solution. 
- Availability of competitive products: According to a study completed in Germany, one of the factors that inhibits German fleet managers from decision making, is the unavailability or lack of information of future EV products on the market (Schlosser-Saeftel-Steinhardt 2019). However, with the recent announcement Ford has just declared an electric product for their famous Transit Light Commercial Vehicle series for 2022, with modern technological advancements to deliver a smart workhorse for their customers around the world (Ford, 2020). eSprinters from Daimler and eCrafter from VW have also announced similar electric products.

\section{Methodology}

This section of the study explores the information sources, the process, and the rationale for conducting this research. It answers the what, how, and why of a research paper (Kallet 2004). The methodology will be based on the publication by McCombes (2019), and includes the following:

- Methodological Approach

- Data Collection

- Analysis

- Tools or materials used

- Justification of Methodological Choices

\section{Methodological approach and justification}

The research question was aimed at understanding the ability of specific companies to understand the concept of value that drives decision making. Decision making by nature is effective when senior management can understand and make informed decisions based on the information and the alternatives presented. The research question aims to understand the link between assessing the total value added in the process of migrating to a carbon neutral fleet. Migrating or upgrading a transport fleet is a significantly cost intensive decision that could be a strategic long-term investment of the company. This thus gives rise to the element of value placed on the process of changing the propulsion option. Both phrases are linked or correlated by the term value; though it is not immediately certain whether it is a positive, negative, or perhaps a zero correlation. 
Correlational research is a type of quantitative research that involves the exploration of 2 or more variables to establish a relationship or correlation between such variables (Chiang-Jhangiani-Price 2015). The quantitative element of this research alludes to the presence of quantitative data that has been collected or measured over a defined period. This type of research will involve trends, pattern recognition or statistical significance/correlation of the variables, using mathematical concepts like the spearman's rank or pearson's correlation coefficient. This research can evaluate the values added to the company by way of decision making and understand the process of migrating to a carbon neutral fleet. Both sets of evaluations can be mutually exclusive set of events.

\section{Data collection \& analysis}

The data to be used for this exercise will be secondary data that has been collected from existing fleet companies, fellow researchers, and other reliable data sources available on transport related websites. A reliable data source is one that consistently collects and publishes relevant data over a period, for the purpose of documentation and supporting future research. There will also be data collected from government related agencies like the Office of National Statistics (ONS) and Department for Transport (DfT) and will be limited to the United Kingdom. Reputable online sources like journals may also be used to verify the submissions found online. The choice of transport companies to use will depend on the quality and availability of relevant data i. e., data from the last 5 years (2015-2020).

Following successful data collection from relevant sources, data sampling was completed to ensure the reliability of the data including missing data points and outliers.

\section{Findings}

Many business organisations have been or are in the process of adopting policies that are favourable to the adoption and acquisition of electric commercial vehicles. Some of these companies, as seen in Figure 5 below, include: 
Figure 5: Fleet customers and their electric commercial vehicle range
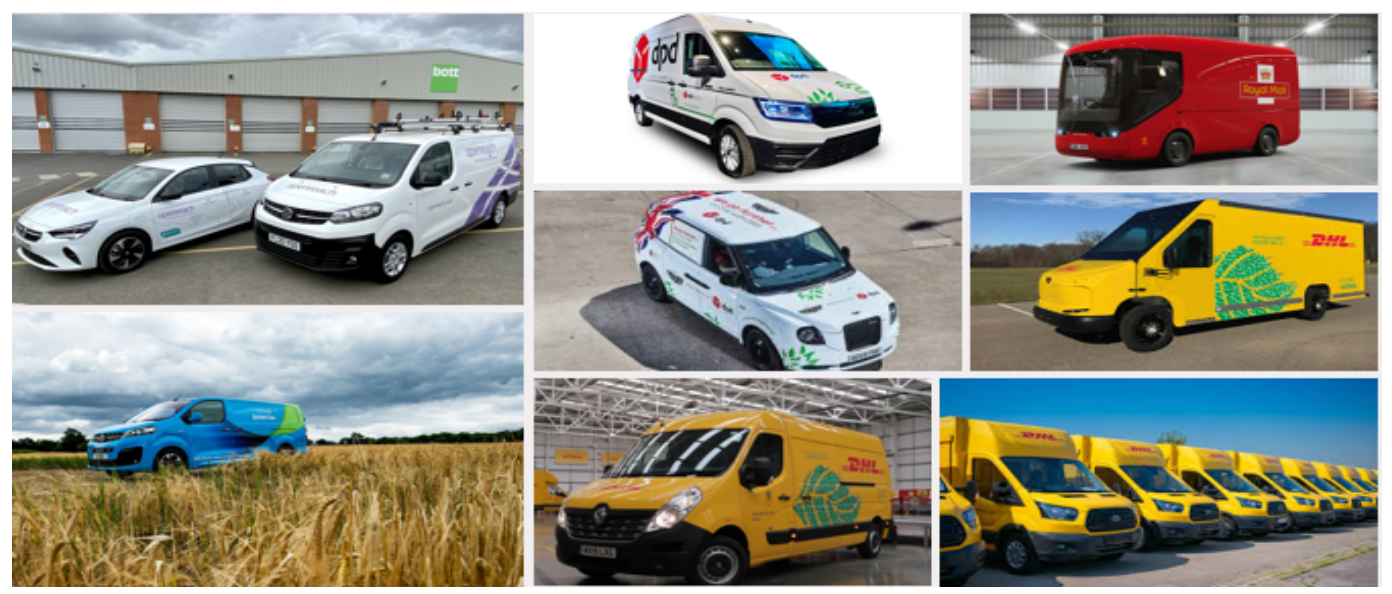

Source: Pictures taken from different websites for the different brands discussed (below)

\section{$D P D$}

Parcel Company DPD signed an agreement with Nissan for 300 electric vans with a plan to have 500 electric vans or $10 \%$ of its fleet (DPD, 2020). This is part of their drive to have the "greenest" delivery fleet in the UK. This decision has saved approximately 2million kilograms of $\mathrm{CO}_{2}$ (CommercialFleet, 2020).

For light commercial vans at target value of $147 \mathrm{~g} / \mathrm{km}$ of CO2 for 2020 (ICCT, 2014), DPD will save about 13.6 million kilometres of real-world driving emissions.

\section{DHL}

DHL has partnered with Ford, Workhorse and Renault to upgrade its fleet of vehicles to include 400 electric vehicles in the UK by 2025 (DHL, 2021). Two reasons highlighted for the upgrade are the ability to be perceived as environmentally friendly, and to meet their sustainability commitment to the environment (DHL, 2021).

\section{BT \& Open Reach}

BT \& Open Reach account for 34,000 fleet vehicles; 27,000 being commercial vehicles and thus are an important volume customer to automobile manufacturers, and more importantly, a significant contributor of tailpipe emissions like CO2. They have committed to upgrading their fleet vehicle network, where economically and technically possible, to achieve an ambitious net-zero status by 2045 (CommercialFleet, 2018). 
Whilst an order of 270 vehicles (Randall 2020) does not represent a significant step, one can only hope that with the speed of the development of electric commercial vehicles, and the different offerings and incentives currently available, the BT Group can take giant strides to electrify their fleet.

\section{Royal Mail}

Royal Mail, the largest commercial fleet vehicle operator in the UK, has about 41,000 vans but has only 295 electric vans in operation (BBC, 2020). Whilst RoyalMail is committed to supporting operational changes to reduce the environmental impact of their business, they have a lot of work and decision making to do, to accelerate the adoption of EV in their fleet. They have announced a partnership with new automobile manufacturer, Arrival, to trial prototype vehicles for limited use. They have also announced further commitments to become a net zero carbon business by 2030 (de Prez 2020).

\section{Centrica (British Gas)}

British Gas ordered 1,000 electric vans and is committed to EV solution for its 12,000 fleet by 2030. This represents one of the biggest commitments in the British EV arena and an incentive for automobile manufacturers to engineer solutions for their needs. The deal translates to a saving of up to $23,000 \mathrm{~g}$ of $\mathrm{CO}_{2}$ for every 100,000 miles of equivalent Nissan Vivaro in the fleet. The vans also have better fuel economy when adjusted for real world driving conditions and no tailpipe emissions, compared to about $183 \mathrm{~g} / \mathrm{km}$ of $\mathrm{CO}_{2}$ at the tailpipe. ${ }^{2}$

\section{Discussion}

\section{Electric vehicles registration}

In the last few years, the drive to EV's and the availability of more EV solutions has led to the increase of EV offerings and sales in Europe. Though the assumption is for the inflexion to be around 2021, there is visible progress made by many automobile manufacturing companies, and also by science and technology that underpins the industry.

2 This assumes an average emission of $142 \mathrm{~g} / \mathrm{km}$ and a conversion of $1.61 \mathrm{~km}$ to $1 \mathrm{mile}$ 
As can be seen from Figure 6 (below), the share of new electric vehicles registration in the 28 members of the EU, has been on an upward projectile. Though the mix of Hybrid and BEV account for 2\%; it is an 8 -fold increase from the vehicle mix in 2012 .

Figure 6: New electric vehicles registration in EU28 - (EEA, 2020)

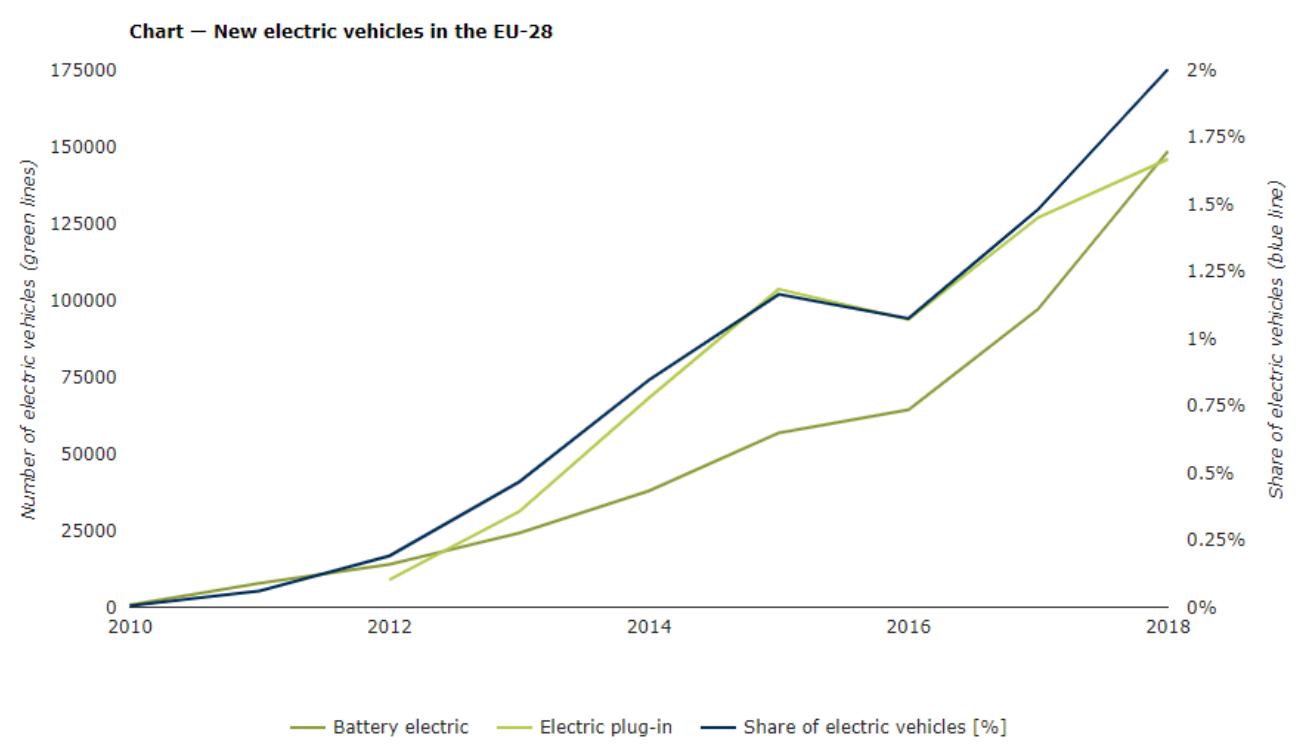

\section{Air quality}

One of the biggest drivers of the push for electrified powertrain propulsion systems is to reduce greenhouse gasses (GHG) that are emitted in the tail pipe of vehicles. These gases include oxides of nitrogen, carbon and sulphur (Sikorska 2015). Whilst the aviation industry is responsible for more $\mathrm{CO}_{2}$ emissions per passenger-kilometre (see Figure 7 - below), and 3\% of the total greenhouse gas emissions in Europe (European Commission, Reducing emissions from aviation, n. d.), the airlines are only required to offset their emissions, not reduce it.

However, the EU fleet-wide average for automobile manufacturers is $95 \mathrm{~g} \mathrm{CO}_{2} / \mathrm{km}$. This implies that any manufacturer that fails to achieve the target will be liable to pay a penalty of $€ 95$ for each $\mathrm{g} / \mathrm{km}$ that exceeds the target (European Commission, Reducing $\mathrm{CO}_{2}$ emissions from passenger cars - before 2020, n. d.). This compels the automobile manufacturers to carefully plan their fleet and accelerate the EV mix in its line up to maintain competitiveness and adhere to the regulations. Though there are opportuni- 
ties to trade credits to achieve the emissions target, adhering to regulatory policy in this instance is a driver for the growth of EV.

It can also be argued that road traffic is a significant contributor to emissions observed as seen in Figure 8 (EEA, 2020). The picture also shows that the annual concentration of $\mathrm{NO}_{2}$ emissions observed in 33 countries ( 28 in EU) in 2017, was consistent with road traffic pollution, with diesel powered vehicles being the biggest contributors. This buttresses the need for capable and affordable alternative propulsions systems.

Figure 7: Emissions from passenger transport (EEA, Carbon dioxide emissions from passenger transport, 2020)

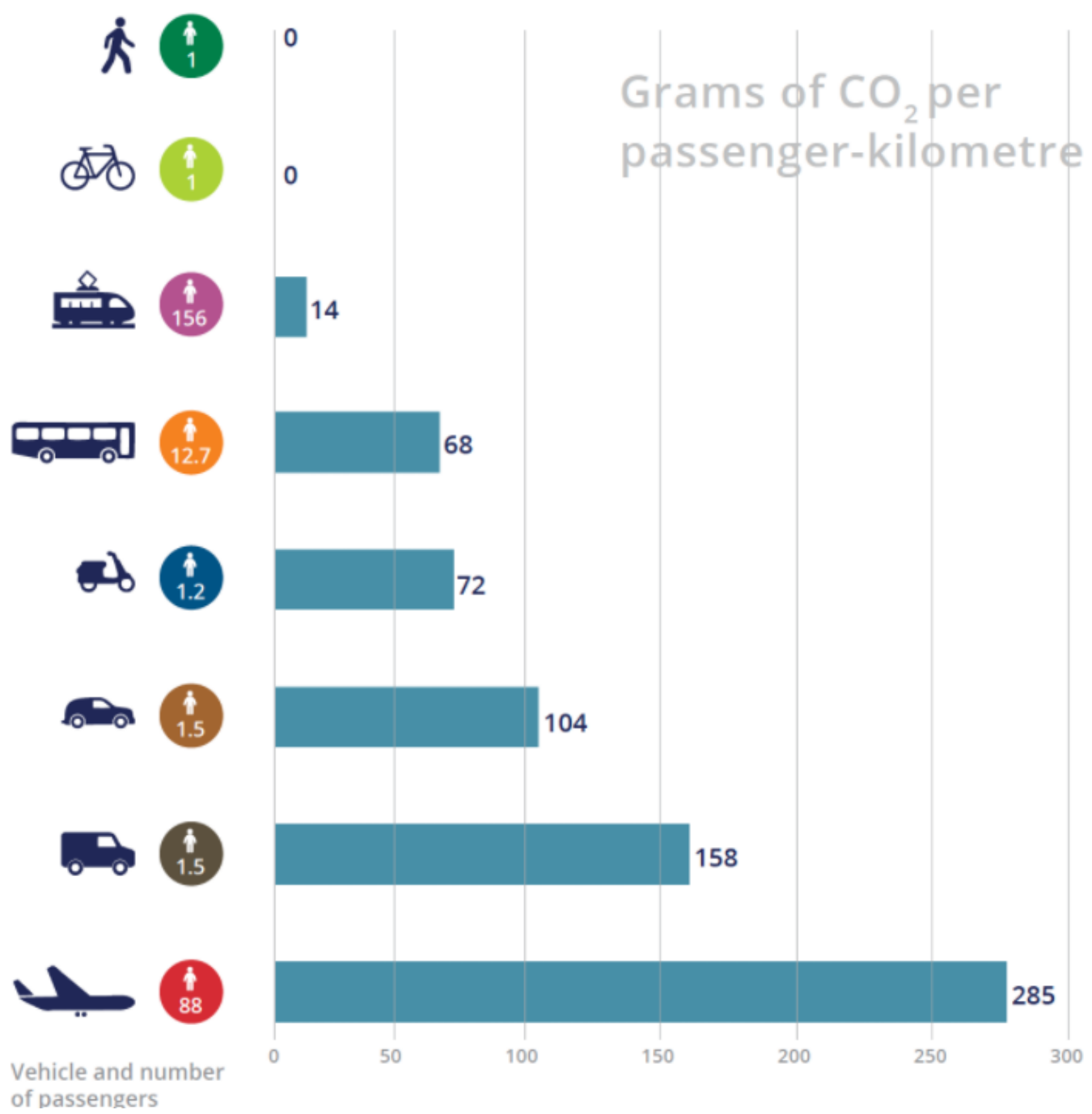


Figure 8. Annual mean $\mathrm{NO}_{2}$ concentrations observed at traffic stations, 2017

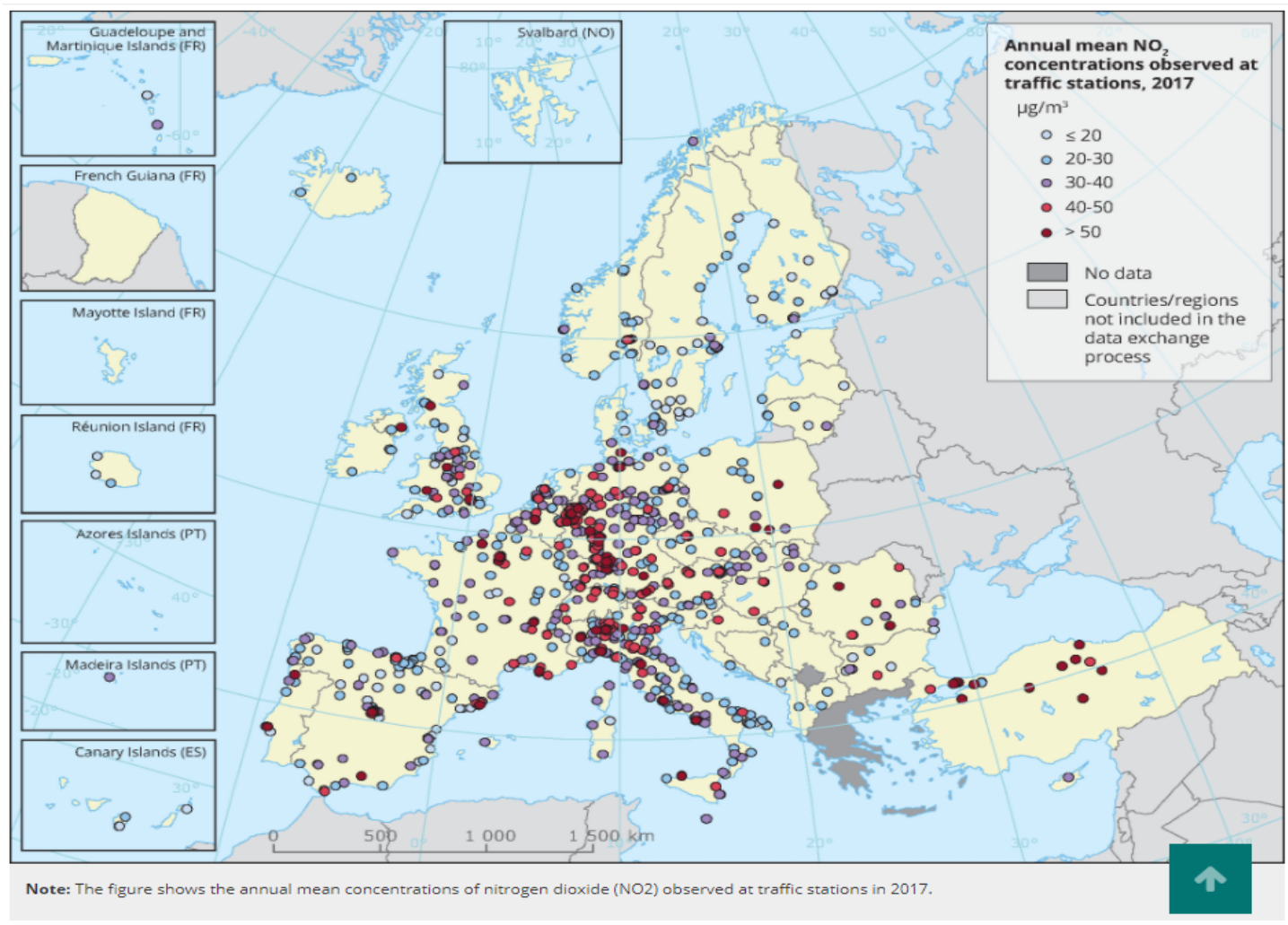

Source: (EEA, 2020)

Drivers for upgrading fleet vehicles

\section{Technology}

There has been a rapid rise in the technological advancements that underpin the development of EV's. Tesla is one of the biggest drivers but so are more disruptive technology companies like Amazon, Nio, Arrival, Rimac, Rivian, Uber and many non-traditional automobile manufacturers. This has led to different partnerships and collaborations that have enhanced the development of EV's, advance in manufacturing technologies, simulations, testing, and software development have also contributed to the quality and speed of the development of the EV's. Fuel cell vehicles are also an alternative propulsion option to carbon neutral vehicles. 


\section{Total Cost of Ownership}

EV's are not cheap to acquire, and they represent an initial significant outlay for both individual and business owners. However, when you factor in the total lifecycle usage of the vehicle over its useful life, then there might be considerations for such choices. This is because EV's have fewer moving parts hence less cost of maintenance, are refuelled cheaper, relative to conventional ICE vehicles and are subject to government grants (in some countries). EV's are not subject to congestion charges, like conventional ICE's are, and can represent significant cost saving if it is the right product.

Therefore, if a fleet transport company is looking to expand in highly regulated areas like Central London, a carefully selected EV alternative might represent a good business decision for the company, the customer, and the environment.

\section{Company brand image}

This is associated with the perception of a company by customers and the wider society. A good brand image is invaluable to a company's reputation and could lead to incremental business without actively doing anything to win such business. If companies have ethical values that reflect a commitment to a sustainable climate, one of the factors in decision making for fleet transportation will be a reciprocated sustainable value for clients. Where there are 2 or more companies trying to attract the same business, the order winner might be the company who is committed to a sustainable environment via a carbon neutral fleet; or a commitment to achieving such targets.

\section{Government Policy}

Different European countries have different sustainability commitments for decarbonisation or being carbon-neutral and a favourable government policy is a big driver for the adoption of electrified propulsion systems. It can be stated that the relative economic wealth of a nation (Figure 9) is positively proportional to the adoption of new electric vehicles (EEA, 2020).

Early adopters like Norway and Sweden have favourable government incentives including favourable tax schemes for EV's, almost rivalling that of ICE. This thus creates an environment where decision making to adopt EV's are less cumbersome and more attractive to the population and companies looking to invest in transport related businesses. This also includes favourable policies for the supply chain industry that 
supports manufacturing, talent acquisition, research and development opportunities, training, and a commitment to providing an enabling environment for these technologies to drive the decarbonisation of vehicles. Data from Centrica Business Solutions shows a correlation between government policy on the ban on the ICE vehicles, and the increased investment in EV propelled vehicles. This is circa $50 \%$ to the tune of $£ 12$ billion (Roberts 2020) and is projected to grow even further.

Figure 9: New electric vehicles by country

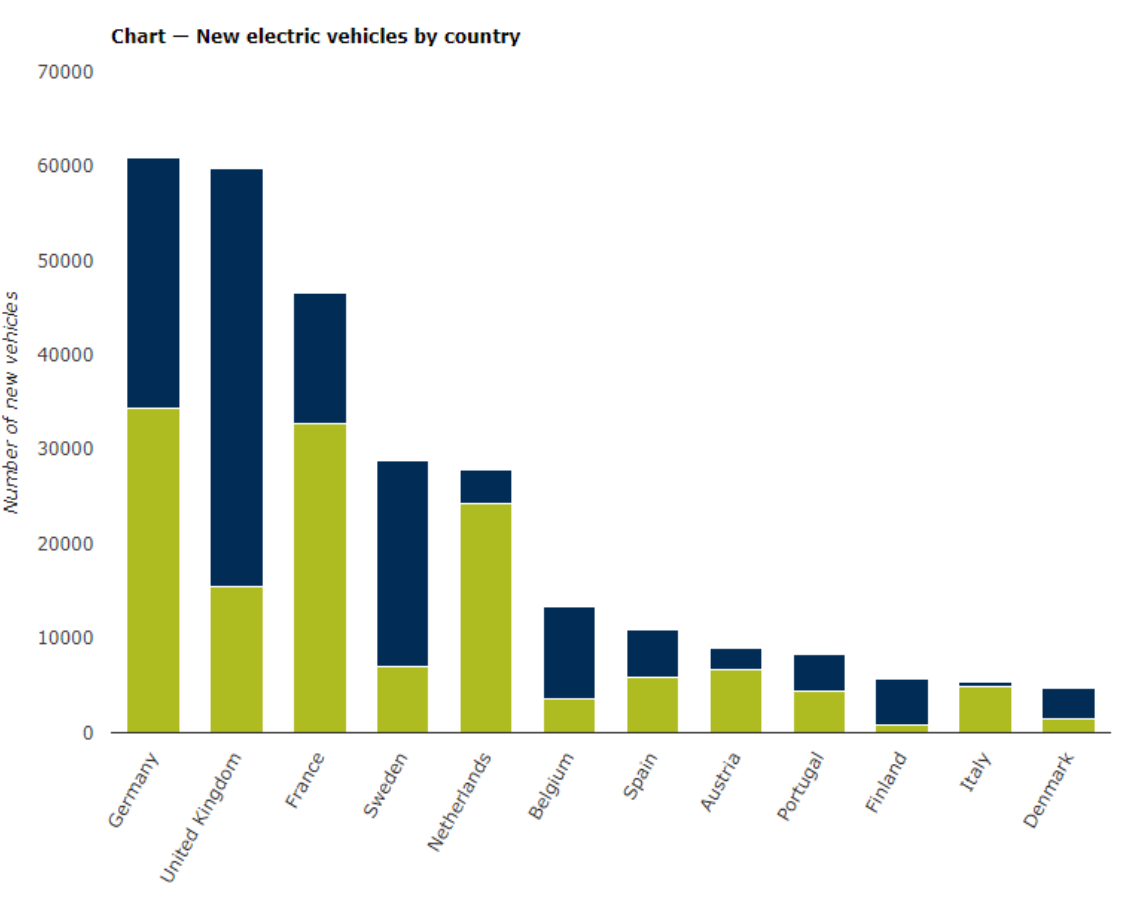

Source: (EEA, 2020)

\section{Battery development}

Battery development has significantly improved in the last few years and this has reduced the "range anxiety" commonly attributed to early generations of EV's. There are also different offerings like range extenders (mHEV) and plug-in hybrids (PHEV) that have internal combustion engines that serve as "insurance" for distance driving. There is also development in the thermal management capabilities of these charging systems to effectively dissipate the heat generated during charging. If the heat is not 
efficiently dissipated, it reduces the efficiency of the battery which in turn reduces the range that the vehicle can travel before a charge is required, and hence the range anxiety. Advancement in power packing and stacking of the batteries has also improved the allowable battery density for different configuration.

\section{Cost of charging EV}

The cost of charging an EV differs from region, type (home or public) and the power rating required for the charge. For the purpose of this research, we will use home charging as documented on the EDF website.

\section{Case study - Real world application:}

An engineer who drives 9000 miles per year to work:

i. EV:

$$
\begin{aligned}
& \text { Installation cost }- \text { up to } £ 1000 \\
& \text { Tariff }-14 \text { p per } \mathrm{kWh} \\
& \text { Conversion }-3.5 \text { miles }=1 \mathrm{kWh} \\
& 9000 \text { miles }=9000 / 3.5 \text { or } 2571 \mathrm{kWh} \\
& \text { Energy cost }-2571 \times 0.14=£ 360
\end{aligned}
$$

$$
\text { Total cost }=1000+360=\mathfrak{E} 1360
$$

ii. ICE:

1 full tank lasts 2 weeks and costs $£ 50$

52 weeks $=52 \times 50 / 2=£ 1300$

From the calculation above, my running cost will be similar regardless of the propulsion option. However, if the driver was driving into a congestion charge zone and pays for parking permit based on emissions, it will be less expensive to own an EV. This should trigger a reconsideration of the need to continue with ICE powered vehicles as opposed to EV's. A similar scenario can play out for electric vans, especially the city centric transport businesses that are subject to emissions surcharge.

While the above illustration is a real-world example of the costs involved, there may be regional and national differences in the running cost of owning a vehicle. 


\section{Current situation}

Following the push for electrification of vehicles, and as a direct consequence of the Paris Declaration on Electro-Mobility and Climate Change (Paris 2015, n. d.), governments and businesses around the world are encouraged to support initiatives to act in the interest of the sustainability of the environment. Figure 10 shows the different scenarios according to some projected studies of the transport sector.

Figure 10: Three different scenarios of the impact of climate change on global transportation

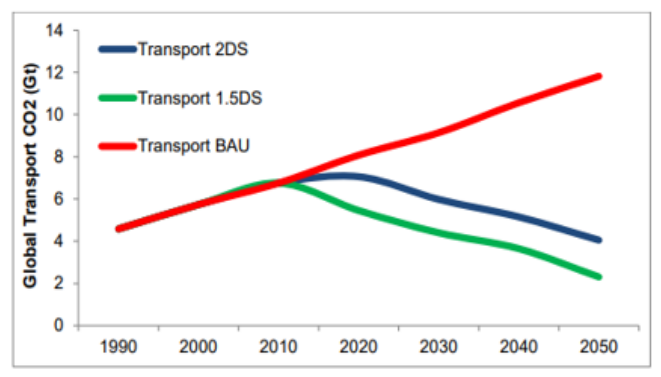

Transport Business-as-Usual

Transport 1.5 degree Celsius scenario

Transport 2 degree Celsius scenario

\section{Adapted from: (Paris Process on Mobility and Climate [PPMC], 2015)}

As has been identified, the transport sector (including domestic air and sea travel) contributed $33 \%$ of all $\mathrm{CO}_{2}$ emissions in the UK (Penistone 2019), though improvement in fuel technology and car efficiency has resulted in a 3.2\% drop relative to the 1990 benchmark. The Euro emissions standards has also helped drive the need for vehicle manufacturers to invest in clean fuel technologies and more efficient vehicle design to reduce the fuel consumption of the vehicles. It has also driven the need to invest in electrified solutions to help reduce the net contribution of GHG's.

Parallel to that, the UK have accelerated their commitments towards the environment by announcing further emission cuts to ensure that the country meets its obligations (Harrabin 2020). One of the ways in which the government will achieve this, is to accelerate the availability of infrastructure and other enablers to reduce the dependence on fossil fuels. This will increase the number and rate of EV adoption and reduce the break-even point where private and commercial EV customers are able to migrate from ICE products. 


\section{Break-even point}

This is the point beyond which the revenue of a business exceeds its costs, and the business is said to be profitable. This is a crucial financial term, as it is an indication of the long-term financial viability of a business. For businesses that own commercial vehicles as part of service delivery to customers, be it logistics or services, the financial equation and incentive to migrate from ICE to carbon-neutral propulsion systems are capital intensive, hence the need for the financial justification of such investments. Therefore, the decision to change propulsion systems is carefully considered based on detailed studies and impact analysis, including any potential government regulation changes that might affect these considerations. This decision-making process can be underpinned by factors like

- Understanding the market trends

- Understanding the capabilities of the electrified propulsion system options, especially for light commercial vehicles and any potential trade-offs e.g., range, payload

- Understanding customer wants and needs

- Understanding the business case

- Understanding additional costs (sometimes hidden) e.g., increase in electricity consumption

\section{Assessment of value added}

As part of management oversight on a company, one of the metrics that can be considered worthy of investing and investigating, is the value added as a result of an action, inaction or decision made. This activity explores the contribution a decision has made to the company. According to Daraban (2017), value added is a combination of:

"Value: what something is worth + Added: an increment".

For this research, value added seeks to understand how a company benefits from the process of decarbonizing its fleet of vehicles to a sustainable carbon neutral one.

Decarbonisation is the conscious reduction of $\mathrm{CO}_{2}$ emissions from the various contributors like tailpipe emissions, renewable and low energy sources, weight reduction and an improved efficiency of energy losses in each system. Figure 11 (below), shows the $\mathrm{CO}_{2}$ emissions of different modes of transport and it is obvious that road transportation contributes a significant amount of $\mathrm{CO}_{2}$ to the atmosphere. 
Figure 11: Transport emissions by mode, 2018 (billion tons $\mathrm{CO}_{2}$ )

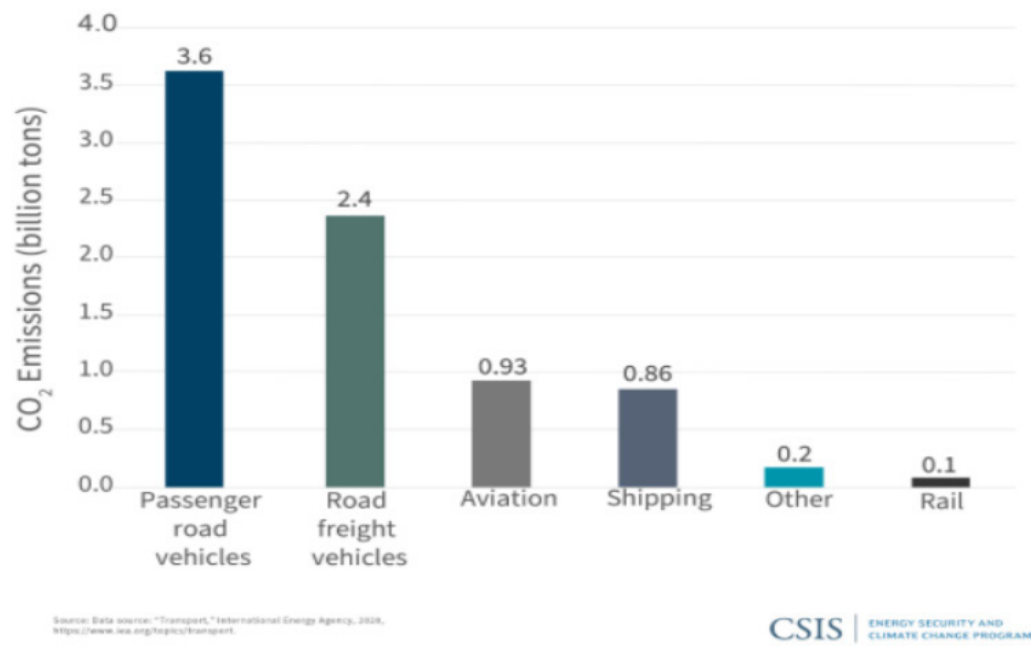

Source: (Naimoli-Tsafos 2020)

Investment decisions, especially in a fiercely competitive and technologically changing world, are carefully planned and managed with all stakeholders including commercial partners. It is now commonplace for these automotive manufacturers to target specific markets or large corporations as partners when unveiling EV solutions in the marketplace. Current examples are Ford and NHS on NHS Ambulance re-entry, Rivian and Amazon, BrightDrop (GM) and FedEx, Arrival and UPS/RoyalMail, Workhorse and DHL, to mention a few. These strategic partnerships not only serve as primary customers for these partners, but they also serve as indirect marketing and sales platforms for other similar businesses in the sector, thereby further realising value to both partners. Value in this case, can be realised through the development of other unique solutions by the automobile manufacturer that may benefit the partner - unintended consequences of business expansion by the vehicle manufacturer.

To assess the total value added in decarbonising a fleet, the following should be part of the decision-making process:

- What is the measure of success? - measuring the value added as a result of a decision-making exercise rooted in our core values and principles.

- What are the values that the company holds true? - Sustainable future and business ethics amongst others. 
- What is the problem definition? - What is the value added by the decarbonisation of the vehicle fleet?

- What are the opportunities for EV adoption? - Which companies are currently playing in the EV arena that we can benchmark our current and future needs with?

- What is the initial capital outlay? - What options exist for EV adopters like our company, who are looking to transition to the EV arena?

- What is the total cost of ownership of the vehicle and the fleet? - How much does it cost including additional installations and management systems required to support the EV fleet? What is the cost difference (delta) with a comparable existing fleet of fossil-powered vehicles?

- What additional infrastructure and installations are required to make the decision a success? - Cost of installing adequate charging systems for the fleet and potentially additional passenger vehicles that may be able to utilise the new infrastructure?

- What partnerships can we explore, in the transition to EV? - Is this an opportunity to invest into the automobile industry, like DHL, Royal Mail and Amazon have done, or can we explore mutually beneficial strategic partnerships like Royal Mail and Arrival.

- What does the future look like for the company? - What timeframe do we need to implement these changes?

- What does the future of EV look like? - Will developments in the EV arena necessitate a progressive review considering technological advancement and the ramification to the transport industry.

- What are the potential legislative changes and what is the timeline? - How long do we have before government policies affect our current business model? When does congestion charge, ULEZ or regional and local ban of fossil-powered vehicles mandate us to enter in the EV arena?

- What other factors need to be considered? - Personnel awareness training, personnel education and knowledge/talent acquisition required to support energy management systems onsite (for large fleets).

The answers to these questions will help guide private and public sector decision makers to identify the opportunities and the value added that can be realised, as a direct consequence of the decision made to decarbonise operational footprint. 


\section{Conclusion}

The adoption of "greener", more sustainable-compliant vehicles like electric vehicles, is a step towards the decarbonisation of the vehicles in our society. The involvement of various governments and businesses, and technological advancement, help accelerate and create the enablers for the adoption of these electric vehicles. The more these enablers contribute to the reduction in the range anxiety, total investment cost, and total cost of ownership, the easier it will be for companies and managers to be able to justify the migration of fleet vehicles from traditional fossil-powered vehicles to sustainable transport models like electric vehicles. Companies can therefore realise "value" through:

- the adoption of sustainable transport solutions like electric vehicles,

- the perception of doing the right thing for the environment (decarbonising the vehicle fleet),

- embracing big data, digital age, and the endless possibilities of transportation/ mobility solutions,

- connectivity and the connected ecosystem of mobility solutions for the management of fleet customers,

- the ability to optimise a given fleet of vehicles based on historical, current, and connected data, modern tools, and expertise.

More studies are being carried out into different aspects of the development of electric vehicles, especially with the amount of mined-material required for systems like the battery and light-weighting materials that can be used to offset traditional manufacturing. This should have a positive impact on the range and capability of EV's. In the future, it is expected that EV's will be as commonplace as traditional fossil-powered vehicles, the significance of which will help to reduce the direct contribution of vehicles to greenhouse gases. For the environmentally savvy, this is the beginning of the realisation of that type of value. 


\section{References}

BBC (2020). Royal Mail trials refitted black cab electric vans. Retrieved November 6, 2020, from https://www.bbc.com/news/technology-53321006

CarbonBrief (2020). Factcheck: How electric vehicles help to tackle climate change. Retrieved November 4, 2020, from https://www.carbonbrief.org/factcheck-howelectric-vehicles-help-to-tackle-climate-change

Chargepoint (n .d.). Driver's Checklist: A Quick Guide to Fast Charging. Retrieved November 4, 2020, from https://www.chargepoint.com/files/Quick Guide to Fast Charging.pdf

Chiang, I.-C. - Jhangiani, R. - Price, P. (2015). Correlational Research. In Research Methods in Psychology (2 ed.). Retrieved November 6, 2020, from https://opentextbc.ca/researchmethods/chapter/correlational-research/

CommercialFleet (2018). BT Group and E.ON pledge electrification of fleets by 2030 . Retrieved November 6, 2020, from https://www.commercialfleet.org/news/vannews/2018/12/10/bt-group-and-eon-pledge-electrification-of-fleets-by-2030

CommercialFleet (2020). DPD: One in 10 vans now fully electric. Retrieved November 5, 2020, from https://www.commercialfleet.org/news/van-news/2020/07/23/dpdone-in-10-vans-now-fully-electric

Daraban, M. (2017). Economic value added - A general review of the concept. Economic Sciences Series, 17(1), 168-173. Retrieved from https://www.researchgate.net/ publication/318792542 Economic Value Added - A General Review of the Concept

De Prez, M. (2020). Royal Mail joins Electric Fleets Coalition. Retrieved from FleetNews: $\quad$ https://www.fleetnews.co.uk/news/latest-fleet-news/electric-fleetnews/2020/11/05/royal-mail-joins-electric-fleet-coalition

DHL (2021). DHL Express brings electric vans to london roads. Retrieved November 6, 2020, from DHL: https://dhlguide.co.uk/sustainability/electricfleet/

DPD (2020). DPD UK takes delivery of 300 Nissan e-NV200 vans to create UK's largest electric vehicles parcel delivery fleet. Retrieved November 6, 2020, from https:// www.dpd.com/group/en/2020/01/30/dpd-uk-takes-delivery-of-300-nissan-env200-vans-to-create-uks-largest-electric-vehicles-parcel-delivery-fleet/

EDF (2020). How much it costs to charge \& run an electric car. Retrieved November 4, 2020, from https://www.edfenergy.com/electric-cars/costs 
EEA (2020). Carbon dioxide emissions from passenger transport. Retrieved November 6, 2020, from https://www.eea.europa.eu/media/infographics/carbon-dioxideemissions-from-passenger-transport/view

EEA (2020). Electric vehicles as a proportion of the total fleet. Retrieved November 6, 2020, from https://www.eea.europa.eu/data-and-maps/indicators/proportion-ofvehicle-fleet-meeting-4/assessment-4

EEA (2020). Exceedances of air quality limit values due to traffic. Retrieved November 6, 2020, from https://www.eea.europa.eu/data-and-maps/indicators/exceedancesof-air-quality-objectives-7/assessment-2

Energy.Gov. (2020). Electric Vehicles. Retrieved November 4, 2020, from https://www. energy.gov/eere/electricvehicles/vehicle-charging

Energy.Gov. (2020). Vehicle Charging. Retrieved November 4, 2020, from https://www. energy.gov/eere/electricvehicles/vehicle-charging

European Commission (n. d.). Reducing $\mathrm{CO}_{2}$ emissions from passenger cars -before 2020. Retrieved November 6, 2020, from https://ec.europa.eu/clima/policies/ transport/-vehicles/cars en

European Commission (n. d.). Reducing emissions from aviation. Retrieved November 6, 2020, from https://ec.europa.eu/clima/policies/transport/aviation en

Ford (2020). Leading the charge: all-electric ford e-transit powers the future of business with next-level software, services and capability. Retrieved from Ford: $\underline{\text { https:// }}$ media. ford.com/content/fordmedia/fna/us/en/news/2020/11/12/all-electric-forde-transit.html

Gordon, J. (2019). Electric Vehicle adoption in the UK: Why make the transition? Electric Vehicles. Retrieved November 5, 2020, from https://www.geotab.com/blog/ electric-vehicle-adoption/

Harrabin, R. (2020). Climate change: UK aim of $68 \%$ emissions cut a "colossal challenge”. Retrieved from BBC News: https://www.bbc.co.uk/news/science-environment-55179008

HelloIota. (n. d.). Technology Adoption. Retrieved November 5, 2020, from https:// www.helloiota.com/articles/technology-adoption

ICCT (2014). EU CO2 emission standards for passenger. Retrieved 2020 November, 2020.

Irena (2020). Decarbonising end-use sectors: Buildings, transport, industry. Which strategies are best? Retrieved November 6, 2020, from https://energypost.eu/decarbonising-end-use-sectors-buildings-transport-industry-which-strategies-are-best/ 
Jansen, S. - Coolen, H. - Goetgeluk, R. (2011). The multi-attribute utility method. In Jansen, S. - Coolen, H. - Goetgeluk, R. (eds.): The Measurement and Analysis of Housing Preference and Choice, 101-125. Delft, Netherlands: Springer Science \& Business Media. doi: https://doi.org/10.1007/978-90-481-8894-9 5

Juneja, P. (n. d.). What is decision making. Retrieved November 5, 2020, from https:// www. managementstudyguide.com/what-is-decision-making.htm.

Kallet, R. (2004). How to write the methods section of a research paper. Respiratory Care, 49(10): 1229-1232. Retrieved November 5, 2020, from https://www. researchgate.net/publication/8267042 How to write the methods section of a research paper

Kumar, P. - Chakrabarty, S. (2020). Total cost of ownership analysis of the impact of vehicle usage on the economic viability of electric vehicles in India. SAGE Journals, 2674(11), 563-572. doi:https://doi.org/10.1177/0361198120947089

Mallette, F. - Khanna, A. - Santha, N. (2018). Accelerating electrification: Critical steps toward electric vehicle mass adoption. Executive Insights, $X X$. Retrieved November 5, 2020, from https://www.lek.com/insights/ei/critical-steps-toward-electric-vehicle-adoption

McCombes, S. (2019). How to write a methodology. Retrieved November 5, 2020, from https://www.scribbr.co.uk/thesis-dissertation/methodology/

McMahon, J. (2019). The 4 lingering obstacles to electric vehicle adoption (and what might overcome them). Retrieved November 5, 2020, from Forbes: https://www. forbes.com/sites/jeffmcmahon/2019/01/27/the-4-lingering-obstacles-to-electricvehicle-adoption-and-what-might-overcome-them/?sh=7604abde5c54

Naimoli, S. - Tsafos, N. (2020). Climate solutions series: Decarbonizing global transport. Retrieved November 6, 2020, from https://www.csis.org/analysis/climate-solutions-series-decarbonizing-global-transport

ONS (2019). Road transport and air emissions. Retrieved October 31, 2020, from Office of National Statistics:.

Paris2015. (n. d.). Paris Declaration on Electro-Mobility and Climate Change \& Call to Action. Retrieved from https://unfccc.int/media/521376/paris-electro-mobilitydeclara-tion.pdf

Penistone, A. (2019). 2018 UK Greenhouse Gas Emissions, Provisional Figures. Retrieved from Department of Business, Energy \& Industrial Strategy: https://assets. publishing.service.gov.uk/government/uploads/system/uploads/attachment data/ file/790626/2018-provisional-emissions-statistics-report.pdf 
Randall, C. (2020). Major fleet order for Vauxhall. Retrieved from electrive.com: https://www.electrive.com/2020/08/11/major-fleet-order-for-vauxhall/

Roberts, G. (2020). UK fleets to invest $£ 12$ bn in electric vehicles. Retrieved from FleetNews: https://www.fleetnews.co.uk/news/fleet-industry-news/2020/03/10/ukfleets-to-invest-12bn-in-electric-vehicles

Schlosser, A. - Saeftel, F. - Steinhardt, L. (2019). The German market for battery-electric light commercial vehicles. Retrieved from https://www.adlittle.com/en/insights/report/german-market-battery-electric-light-commercial-vehicles

Sikorska, P. E. (2015). The need for legal regulation of global emissions from the aviation industry in the context of emerging aerospace vehicles. International Comparative Jurisprudence, 1(2), 133-142. doi: https://doi.org/10.1016/j.icj.2015.12.0-04

Statista. (2020). Vehicles \& Road Traffic. Retrieved November 4, 2020, from https:// www. statista.com/statistics/673575/charging-locations-electric-vehicles uk/\#: :text=-UK\%3A\%20 number\%20of\%20charging\%20locations $\% 20$ for $\% 20$ electric \%20-vehicles\%20from\%202018\%2D2020\&text=In\%20the\%20period\%20 of $\% 20$ consideration, charging $\% 20$ locations $\% 20 \mathrm{in} \% 2$

Tesla (2020). About Tesla. Retrieved November 5, 2020, from https://www.tesla.com en EU/about

UMass (2020). Decision-making process. Retrieved November 5, 2020, from https:// www. umassd.edu/fycm/decision-making/process/\#: :text= Decision\%20making $\% 20$ is $\% 20$ the $\% 20$ process, relevant $\% 20$ information $\% 20$ and $\% 20$ defining $\% 20$-alternatives

Wu, G. - Inderbitzin, A. - Bening, C. (2015). Total cost of ownership of electric vehicles compared to conventional vehicles: A probabilistic analysis and projection across market segments. Energy Policy, 80, 196-214. doi: https://doi.org/10.1016/j. enpol.2015.02.004

Zap-Map (2020). EV Charging Stats 2020. Retrieved November 4, 2020, from https:// www.zap-map.com/statistics/ 